\title{
OPTIMALISASI PENANGANAN KELUHAN PASIEN UNTUK MENINGKATKAN KEPUASAN PASIEN PADA RUMAH SAKIT
}

\author{
Makmur Sujarwo \\ Universitas Pancasakti Tegal \\ Prodi Manajemen Fakultas Ekonomi dan Bisnis \\ makmursujarwo@gmail.com \\ Subekti \\ Universitas Pancasakti Tegal \\ Prodi Manajemen Fakultas Ekonomi dan Bisnis \\ subekti.ups@gmail.com
}

\begin{abstract}
Abstrak
Penelitian ini bertujuan untuk mengetahui bagaimana penanganan keluhan pasien telah dioptimalkan pada rumah sakit di kota Tegal sehingga dapat meningkatkan kepuasan pasiennya. Sampel yang digunakan dalam penelitian ini sebanyak 145 pasien rumah sakit, baik pasien rawat inap maupun pasien rawat jalan di rumah sakit-rumah sakit kota Tegal. Responden menjawab pertanyaan-pertanyaan mengenai variabel-variabel yang diteliti, kemudian dianalisis dengan menggunakan Uji Regresi Berganda menggunakan SPSS 22.

Variabel-variabel dalam penelitian ini meliputi ; visibility, accesibility, dan responsiveness. Penelitian ini menunjukkan bahwa ketiga variabel berpengaruh positif dan signifikan terhadap peningkatan kepuasan pasien. Masing-masing variabel ditunjukkan dengan nilai regresi 0.348 untuk variabel visibility, 0.395 untuk variabel accesibility dan 0.233 untuk variabel responsiveness dengan tingkat signifikan sebesar 0.000 artinya kurang dari 0.05 sehingga signifikan.

Sehingga pihak rumah sakit disarankan untuk mengoptimalkan; kualitas petugas customer service sehingga keluhan pasien dapat tertangani secara langsung, menyedikan layanan telepon/call center/contact center sehingga pasien dapat mengetahui informasi tentang praktek dokter, ketersediaan kamar dll, menyediakan website rumah sakit sehingga pasien dapat mengupdate informasi dan menyediakan kotak saran dan kritik sehingga pasien dapat memberikan saran dan kritik secara tertutup, memberikan layanan yang mudah kepada pasien,menangani pasien secara cepat dan tidak birokratis sehingga pasien tidak di ping pong serta karyawan, paramedis dan dokter membantu pasien dengan tanggap dan cekatan, dan pelayanan administrasi yang tidak bertele-tele.
\end{abstract}

Kata Kunci :Kepuasan dan keluhan pasien, accesibility,visibility, dan responsiveness. 


\section{PENDAHULUAN}

Pasien sebagai konsumen pada sebuah rumah sakit sangat mengharapkan pelayanan kesehatan yang optimal. Ketika kinerja pelayanan rumah sakit tidak sesuai yang diharapkan maka pasien akan kecewa. Kekecewaan tersebut akan mengakibatkan perilaku konsumen untuk mengurangi penggunaan jasa layanan pada rumah sakit tersebut. Kekecewaan merupakan bagian dari ketidakpuasan konsumen terhadap kinerja perusahaan yang diharapkan. Menurut Kotler, (1996), kepuasan pelanggan adalah tingkat perasaan seseorang setelah membandingkan kinerja ( atau hasil) yang ia rasakan dibandingkan dengan harapannya. Sedangkan menurut Engel , (1990), kepuasan pelangagn merupakan evaluasi purnabeli dimana alternatif yang dipilih sekurang-kurangnya sama atau melampaui harapan pelanggan, sedangkan ketidakpuasan timbul apabila hasil (outcome) tidak memenuhi harapan.

Rumah sakit yang mendapatkan kepuasan pelanggan yang tinggi tentu akan dapat memenangkanpersaingan dengan kompetitornya. Demikian pula sebaliknya, jika kepuasan pelanggannya rendah maka rumah sakit tersebut tidak dapat memenangkan pasar persaingan dengan kompetitornya. Menurut Levitt (1987), syarat yang harus dipenuhi oleh suatu perusahaan agar dapat sukses dalam persaingan adalah berusaha mencapai tujuan untuk menciptakan dan mempertahankan pelanggan.
Penelitian yang dilakukan Andri Irawan (2016), menyimpulkan bahwamanajemen komplain di Rumah SakitUmum Daerah Merauke belum menunjukan hasil yang baik.Hanya ada kotak saran sebagai alternativ menerima keluhan yang masuk secara tidak langsung, dan dalam penanganannya belum maksimal. Hal ini terbukti dari masih lambatnya pengelolaan serta tidak adanya penyampaian informasi dari rumah sakit kepada pasien bahwa keluhan yang masuk sudahditangani

(http://ejournal.unmus.ac.id/index.php/societas ,Volume 5 No 01 Tahun 2016).Berdasarkan hasil temuan data yang dilakukan oleh Honny Nur Afidah ( 2013), menyimpulkan bahwa mekanisme komplain di RSU Haji Surabaya berjalan secara efektif, ditunjukan oleh aspek accesible, empathy,dan fairness dalam menangani keluhan pelanggan berjalan secara optimal dan sesuai dengan prosedur yang berlaku(Kebijakan dan Manajemen Publik,ISSN, 2303-341X ,Volume 1, No.1, Januari 2013).

Dalam Strategi Pemasaran, Fandy Tjiptono (2008) terdapat beberapa strategi yang dapat dipadukan untuk meraih dan meningkatkan kepuasan pelanggan, salah satunya adalah strategi penanganan keluhan yang efisien ( Schnaars ,1991).

Rumah sakit di kota Tegal, baik milik pemerintah maupun swasta terlihat cukup bersaing dalam melayani pasiennya. Pembangunan gedung baru yang cukup representatif merupakan salah satu bukti 
sebagai tangibles ( bukti fisik ) agar pelayanan kepada pasien lebih optimal. Adanya keluhankeluhan pasien yang tidak tertangani dengan baik akan menurunkan kualitas layanan rumah sakit tersebut. Jika kualitas layanan kepada pasien menurun tentu akan menimbulkan ketidakpuasan atau kekecewaan kepada pasien. Tentu itu pula yang dapat meningkatkan persaingan antar rumah sakit tersebut.Dari hal inilah, peneliti merasa perlu untuk melakukan penelitian bagaimana rumah sakit di Kota Tegal telah mengoptimalkan strategi penanganan keluhan pasien yang efektif agar dapat meningkatkan kepuasan pelanggannya.

\section{Tujuan Penelitian}

Tujuan diadakannya penelitian ini adalah untuk mengetahui sejauh mana strategi penanganan keluhan pasien yang efisien telah di implementasikan pada rumah sakit-rumah sakit di Kota Tegal sehingga dapat meningkatkan kepuasan pelanggannya.

\section{Tinjauan Literatur Dan Pengembangan Hipotesis}

\section{Definisi kepuasan pelanggan}

Menurut Day ( dalam Tse dan wilton, 1988), kepuasan atau ketidakpuasan pelanggan adalah respon pelanggan terhadap evaluasi ketidaksesuaian yang dirasakan antara harapan sebelumnya dan kinerja aktual produk yang dirasakan setelah pemakaianya. Engel , (1990), kepuasan pelangagn merupakan evaluasi purnabeli dimana alternatif yang dipilih sekurang-kurangnya sama atau melampaui harapan pelanggan, sedangkan ketidakpuasan timbul apabila hasil (outcome) tidak memenuhi harapan.

Menurut Kotler, et al (1990) menyatakan bahwa kepuasan pelanggan adalah tingkat perasaan seseorang setelah membandingkan kinerja yang ia rasakan dibandingkan dengan harapannya. Sementara Pohan (2007) menyebutkan bahwa kepuasan pasien adalah tingkat perasaan pasien yang timbul sebagai akibat dari kinerja layanan kesehatan yang diperolehnya, setelah pasien membandingkan dengan apa yang diharapkannya. Krowinsky dan Steiber ( 1996) mengajukan sepuluh elemen sebagai faktor-faktor yang perlu diamati dalam mengkaji kepuasan pasien, yaitu: keterjangkauan (accessibility), ketersediaan sumber daya (availability of resources), kontinuitas pelayanan (continuity of care), efektivitas (terhadap hasil) (efficacy atau outcomes of care), keuangan (finance), humanitas (humaness), ketersediaan informasi (information gathering), pemberian informasi (information delivering), kenyamanan lingkungan (pleasantness of surrounding), serta kualitas dan kompetensi petugas (quality atau competence).

\section{Peningkatan Kepuasan Pelanggan}

Salah satu strategi peningkatan kepuasan pelanggan yang disampaikan oleh Fandy Tjiptono ( 2008) yaitu strategi penanganan keluhan yang efisien. Strategi penanganan 
keluhan yang efisien merupakan penanganan keluhan memberikan peluang untuk mengubah seorang pelanggan yang tidak puas menjadi pelanggan produk perusahaan yang puas ( atau bahkan menjadi pelanggan abadi). Proses penanganan keluhan yang efektif dimulai dari identifikasi dan penentuan sumber masalah yang menyebabkan pelanggan tidak puas dan mengeluh. Sumber masalah perlu dibatasi, ditindaklanjuti, dan diupayakan agar dimasa mendatang tidak timbul masalah yang sama.

Terdapat empat aspek penting dalam penanganan keluhan, yaitu :

a. Empati terhadap pelanggan yang marah

b. Kecepatan dalam penanganan keluhan

c. Kewajaran atau keadilan dalammemecahkan permasalahan atau keluhan.

d. Kemudahan bagi konsumen untuk menghubungi perusahaan.

\section{Penelitian Terdahulu}

Penelitian yang dilakukan Lina Marliana ( 2017 ) menyimpulkan bahwa Tata kelola Keluhan Pasien di Rumah Sakit Umum Daerah A. M. Parikesit Tenggarong Seberang sudah dikelola dengan baik sesuai dengan PrinsipPrinsip Dasar Tata Kelola yang baik yaitu Transparansi, Akuntabilitas, Responsibilitas, Independensi, dan Kesetaraan dan Kewajaran (Jurnal Administrative Reform, Vol 5, No 2, Juni 2017).

Sementara penelitian yang dilakukan oleh Agung Utama tentang Analisis Pengaruh Persepsi Kualitas Pelayanan Terhadap
Kepuasan Pelanggan Rumah Sakit Umum Cakra Husada Klaten, menunjukkan pelanggan (pasien) RSU Cakra Husada Klaten memiliki persepsi yang memuaskan atas kualitas pelayanan yang diterimanya (dirasakan) yang meliputi dimensi tangible, reliability, responsiveness, assurance, dan empath, OPSI, Vol. 1, No. 2, Desember 2003: $96-110$.

Penelitian yang dilakukan oleh Muh.Anwar Hafid ( 2014) menyimpulkan bahwa kinerja perawat mempunyai hubungan terhadap kepuasan pasien pengguna kartu yankestis dalam pelayanan keperawatan diRSUD Syech yusuf Kabupaten Gowa ( Jurnal Kesehatan : Volume VII no.2 /2014).

Sedangkan penelitian yang dilakukan Muhadi ( 2016) Studi Penanganan Komplain Pasien Di Instalasi Rawat Jalan (Irj) Rsud Dr. Soetomo Pasien mengeluh tentang antrian yang lama dan sikap petugas yang kurang responsif. Dimana pasien merasa kesulitan menyesuaikan persyaratan administrasi pasien BPJS kesehatan dengan model kepesertaan lama atau asuransi kesehatan. Sosialisasi yang kurang menyebabkan informasi yang beredar mengenai prosedur pendaftaran dan pemanfaatan BPJS kesehatan tidak relevan dan membingungkan. Akibatnya tidak jarang staf rumah sakit menerima komplain atau kemarahan pasien, dituduh mempersulit, bahkan dituding mencari keuntungan.

Hasil penelitian Andri Irawan, dkk ( 2016) menunjukan bahwa manajemen komplain di Rumah Sakit Umum Daerah Merauke belum 
menunjukan hasil yang baik. Hanya ada kotak saran sebagai alternatif menerima keluhan yang masuk secara tidak langsung, dan dalam penanganannya belum maksimal. Hal ini terbukti dari masih lambatnya pengelolaan serta tidak adanya penyampaian informasi dari rumah sakit kepada pasien bahwa keluhan yang masuk sudah ditangani.Yang menjadi faktor pendukung dalam manajemen komplain di RSUD Merauke adalah adanya SOP dan fasilitas komplain. Sedangkan yang menjadi faktor penghambat adalah sumber daya manusia yang masih lemah dan sosialisasi tentang komplain yang belum berjalan. (http://ejournal.unmus.ac.id/index.php/societas Volume 5 No 01 Tahun 2016)

Berdasarkan hasil uraian di atas maka hipotesis yang diajukan adalah :

H1: Optimalisasi penanganan keluhan pasien dengan variabel accesibilty berpengaruh positif terhadap peningkatan kepuasan pasien rumah sakit di Kota Tegal.

H2: Optimalisasi penanganan keluhan pasien dengan variabel visibility berpengaruh positif terhadap peningkatan kepuasan pasien rumah sakit di Kota Tegal.

H3: Optimalisasi penanganan keluhan pasien dengan variabel responsiveness berpengaruh positif terhadap peningkatan kepuasan pasien rumah sakit di Kota Tegal.

\section{Metode Penelitian}

\section{Kerangka Pemikiran Teoritis}

Kerangka pemikiran teoritis ini menggambarkan adanya optimalisasi penanganan keluhan pasien yang efisien dengan variabel-variabel accesibility, visibility, dan responsiveness berpengaruh positif terhadap peningkatan kepuasan pelanggan pada rumah sakit di Kota Tegal.

Gambar 1. Kerangka Pemikiran Teoritis

\section{Peningkatan Kepuasan Pasien} Pada Rumah sakit

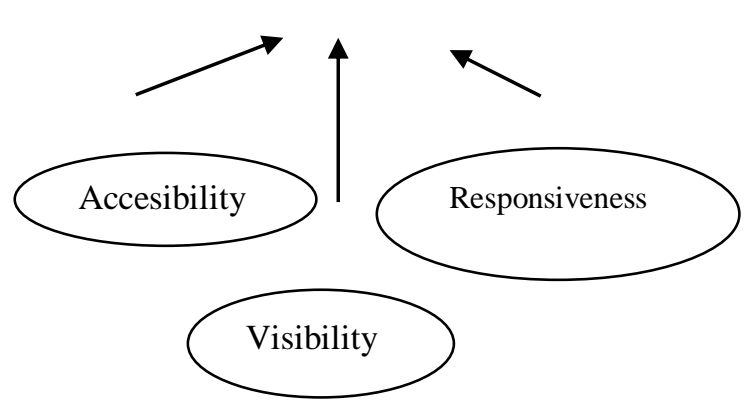

\section{Jenis dan Sumber Data}

Data primer dalam penelitian ini diperoleh secara langsung dari pasien ( baik rawat inap maupun rawat jalan) sebagai responden yang ada di rumah sakit Kota Tegal.Populasi yang digunakan dalam penelitian ini adalah rumah sakit yang ada di kota Tegal, yaitu RSUD Kardinah dan RSUI Harapan Anda. Menurut Gay dan Diehl (1992) pada kajian untuk kelas bisnis dan manajemen memberikan saran ukuran sampel minimal untuk penelitian korelasi, jumlah sampel minimum adalah 30 
subjek. Dalam penelitian ini jumlah sampel yang diolah sebanyak 145 sampel dengan pasien dari beberapa rumah sakit tersebut sebagai responden.

\section{Metode Pengumpulan Data}

Metode pengumpulan data yang digunakan dalam penelitian ini adalah menggunakan kuesioner. Dengan kuesioner ini, responden diharapkan membaca dan menjawab pertanyaan yang diajukan oleh peneliti.Setelah itu, diharapkan langsung adanya tanggapan dari responden dan dapat langsung dikumpulkan oleh peneliti setelah mereka mengisinya. Pertanyaan-pertanyaan dalam kuesioner dibuat dengan menggunakan skala likert 5 poin (1: Sangat Tidak Setuju hingga 5 : Sangat Setuju).

\section{Teknik Analisis Data}

Tekhik analisis yang digunakan dalam penelitian ini adalah menggunakan teknik analisis regresi untuk mengolah dan membahas data yang telah diperoleh dan unutk menguji hipotesis yang diajukan.Hair et al (1998) menyatakan bahwa regresi berganda merupakan teknik statistik yang menjelaskan keterkaitan antara variabel terikat dengan beberapa variable bebas. Regresi berganda juga dapat memperkirakan kemampuan prediksi dari serangkaian variabel bebas terhadap variabel terikat ( Hair et all, 1995). Berikut ini adalah persamaan regresi yang digunakan dalam penelitian ini : $\mathrm{Y}=\mathrm{a}+\mathrm{b} 1 \mathrm{X} 1+\mathrm{b} 2 \mathrm{X} 2+\mathrm{b} 3 \mathrm{X} 3+\ldots . . \mathrm{bkXik}+\mathrm{ei}$
Keterangan :Y : Kepuasan Pasien,X1 : visibility, $\quad \mathrm{X} 2$ :accesibility , $\mathrm{X} 3$ : responsiveness, a : Konstanta , b 1, b2 : Koefisien Regresi, e : error

\section{Pengujian Hipotesa}

Uji t (Uji Parsial)

Uji t yaitu suatu uji untuk mengetahui pengaruh visibility, acesibility, dan responsiveness, terhadap peningkatan kepuasan pasien dalam memilih jasa rumah sakit di kota Tegal secara parsial.

\section{Uji F (Uji Simultan)}

Uji F yaitu suatu uji untuk mengetahui visibility, acesibility, dan responsiveness, terhadap peningkatan kepuasan pasien dalam memilih jasa rumah sakit di kota Tegal secara simultan.

\section{Dimensionalisasi Variabel}

1. Variabel visibility terdiri dari dimensi tersedianya customer service departemen dengan indikatornya adanya penanganan keluhan pasien secara langsung ; dimensi tersedianya telepon/call center/contact center dengan indikatornya pasien dapat melakukan call setiap saat untuk mengetahui informasi tentang praktek dokter, ketersediaan kamar dll ; dimensi tersedianya email, website rumah sakit dengan indikatornya pasien dapat mengupdate informasi ; dimensi tersedianya kotak saran dan kritik dengan indikatornya pasien dapat memberikan saran dan kritik secara tertutup ; 
2. Variabel accesibility meliputi dimensi dimensi layanan mudah dengan indikatornya layanan mudah diakses pasien ; dimensi kecepatan penanganan pasien dengan indikatornya pasien dapat tertangani secara cepat oleh pihak rumah sakit ; dan dimensi tidak birokratis dengan indikatornya pasien tidak di ping pong

3. Variabel responsiveness terdiri dari dimensi variabel paramedis dan dokter membantu pasien dengan tanggap dengan indikatornya meliputi ; pasien dibantu dan dilayani oleh karyawan rumah sakit dengan tanggap, pelayanan administrasi yang tidak berteletele, petugas para medis dan dokter menangani pasien dengan cekatan.

\section{Hasil dan Pembahasan}

Objek penelitian ini adalah para pasien baik pasien rawat jaga maupun pasien rawat inap ( sebagai responden ) yang ada pada rumah sakit- rumah sakit di kota Tegal. Kuesioner disebar sebanyak 160 buah, dan kembali ke peneliti sebanyak 145 buah kuesioner. Kuisioner disebarkan pada pasien-pasien rumah sakit di kota Tegal yaitu RSUD Kardinah dan RSUI Harapan Anda. Dari survey yang dilakukan, data terkumpul dan diolah dengan menggunakan IBM SPSS Statistics 22.

\section{Hasil Uji Validitas}

Berdasarkan hasil Uji Validitas diketahui bahwa semua indikator adalah valid.Nilai korelasi dari masing-masing indikator dengan probabilitas korelasi [sig. (2-tailed)] sebesar 0,000. Sesuai kriteria sebelumnya, maka semua indikator diatas adalah valid, karena nilai probabilitas korelasi [sig.(2-tailed) < dari taraf signifikan $(\alpha)$ sebesar 0,05 . Dengan demikian masing-masing indikator pada variabel tersebut dapat dilakukan kepada langkah penghitungan selanjutnya.

\section{Hasil Uji Reliabilitas}

Dari hasil uji reliabilitas, menunjukan bahwa nilai Cronbach Alpha sebesar 70,9\% yang menurut kriteria Nunnallly (1994) telah melebihi nilai $r$ tabel atau nilai Cronbach Alpha $>0.70$. Maka hasil data memiliki tingkat reliabilitas yang baik, atau dengan kata lain data hasil angket dapat dipercaya.

Tabel.1

\section{Hasil Uji Reliabilitas}

\section{Reliability}

Statistics

\begin{tabular}{|c|c|c|}
\hline $\begin{array}{c}\text { Cronbach's } \\
\text { Alpha }\end{array}$ & $\begin{array}{c}\text { Cronbach's Alpha Based } \\
\text { on Standardized Items }\end{array}$ & $\begin{array}{c}\text { N of } \\
\text { Items }\end{array}$ \\
\hline .701 & .709 & 4 \\
\hline
\end{tabular}

Sumber : hasil olahan data SPSS

\section{Hasil Uji Regresi Linear Berganda}

Dari olahan data menggunakan IBM SPSS Statistics 22, regresi linier berganda antaravariabel visibility, acesibility, dan responsiveness untuk dapat meningkatkan kepuasan pasien pada rumah sakit di kota 
Tegal ( Y) dapat diperoleh hasil sebagai berikut :

$\mathrm{Y}=0.155+0.348(\mathrm{X} 1)+0.395(\mathrm{X} 2)+0.233(\mathrm{X} 3)$

Tabel 2

\section{Uji koefisien Regresi}

\section{Coefficients $^{\mathrm{a}}$}

\begin{tabular}{|c|c|c|c|c|c|}
\hline \multirow[b]{2}{*}{ Model } & \multicolumn{2}{|c|}{$\begin{array}{l}\text { Unstandardize } \\
\text { d Coefficients }\end{array}$} & \multirow{2}{*}{$\begin{array}{l}\text { Standar } \\
\text { dized } \\
\text { Coeffic } \\
\text { ients }\end{array}$} & \multirow[b]{2}{*}{$\mathrm{t}$} & \multirow[b]{2}{*}{ Sig. } \\
\hline & B & $\begin{array}{l}\text { Std. } \\
\text { Error }\end{array}$ & & & \\
\hline 1 (Constant) & .155 & .316 & & .491 & .624 \\
\hline Visibility & .348 & .050 & .397 & 6.966 & .000 \\
\hline Accesibility & .395 & .058 & .418 & 6.843 & .000 \\
\hline $\begin{array}{l}\text { Responsive } \\
\text { ness }\end{array}$ & .233 & .055 & .252 & 4.272 & .000 \\
\hline
\end{tabular}

Sumber : Olahan Data SPSS

Hasil persamaan regresi berganda tersebut di atas memberikan pengertian bahwa :

1. Konstanta sebesar 0,155 menyatakan jika variabel independen dianggap konstan, maka rata-rata peningkatan kepuasan pasien pada rumah sakit di kota Tegal sebesar 0,155 .
2. Nilai koefisien regresi untuk variabel visibility (X1) sebesar 0,348 mempunyai arti bahwa jika visibility (X1) pada rumah sakit tersebut lebih ditingkatkan, maka rumah sakit tersebut dapat meningkatkan kepuasan pasiennya.

3. Nilai koefisien regresi untuk variabel accesibility(X2) sebesar 0,395 mempunyai arti bahwa jika accesibility (X2) pada rumah sakit tersebut lebih ditingkatkan, maka rumah sakit tersebut dapat meningkatkan kepuasan pasiennya.

4. Nilai koefisien regresi untuk variabel responsiveness (X3) sebesar 0,233 mempunyai arti bahwa jika responsiveness (X3) pada rumah sakit tersebut lebih ditingkatkan, maka rumah sakit tersebut dapat meningkatkan kepuasan pasiennya.

\section{Koefisien Determinasi ( $\mathbf{R}^{2}$ )}

Besarnya prosentase variabel peningkatan kepuasan pelanggan mampu dijelaskan oleh variabel bebas (koefisien determinasi) ditunjukkan dengan nilai Adjusted R Square (R2) yaitu sebesar 0,566 menggunakan R2 karena variabel bebas dalam penelitian ini lebih dari satu, dalam hal ini dapat diartikan bahwa peningkatan kepuasan pasien pada rumah sakit dapat dijelaskan oleh variabel visibility, accesibility,dan responsiveness dengan nilai sebesar $56,6 \%$, sedangkan sisanya dijelaskan oleh variabel lain yang tidak diteliti dalam penelitian ini. 


\section{Koefisien determinasi}

Sumber olahan data SPSS

\section{Hasil Pengujian Hipotesis}

Hasil Pengujian Hipotesis Secara Parsial dengan Uji-t

Hasil uji persial (uji t) yang dapat dijelaskan sebagai berikut :

1. Hipotesis 1 : menguji pengaruh visibility terhadap peningkatan kepuasan pasien pada rumah sakit di kota Tegal menunjukkan hasil bahwa visibility mempunyai pengaruh positif dan signifikan terhadap peningkatan kepuasan pasien rumah sakit di kota Tegal. Hal ini ditunjukkan oleh koefisien regresi sebesar 0,348 dan tingkat signifikansi sebesar $0,000<0,05$.

2. Hipotesis 2 : menguji pengaruh accesibility terhadap peningkatan kepuasan pasien pada rumah sakit di kota Tegal menunjukkan hasil bahwa accesibility mempunyai pengaruh positif dan signifikan terhadap peningkatan kepuasan pasien rumah sakit di kota Tegal. Hal ini ditunjukkan oleh koefisien regresi sebesar 0,395 dan tingkat signifikansi sebesar $0,000<0,05$.

3. Hipotesis3 : menguji pengaruh responsiveness terhadap peningkatan kepuasan pasien pada rumah sakit di kota Tegal menunjukkan hasil bahwa responsiveness mempunyai pengaruh positif dan signifikan terhadap peningkatan kepuasan pasien rumah sakit di kota Tegal.
Hal ini ditunjukkan oleh koefisien regresi sebesar 0,233 dan tingkat signifikansi Model Summary

\begin{tabular}{|c|c|c|c|c|}
\hline Model & $\mathrm{R}$ & $\begin{array}{c}\mathrm{R} \\
\text { Square }\end{array}$ & $\begin{array}{c}\text { Adjusted R } \\
\text { Square }\end{array}$ & $\begin{array}{c}\text { Std. Error of } \\
\text { the Estimate }\end{array}$ \\
\hline 1 & $.759^{\mathrm{a}}$ & .575 & .566 & .325 \\
\hline
\end{tabular}

a. Predictors: (Constant), Responsiveness, Visibility,

Accesibility

b.Dependent Variable: Peningkatan Kepuasan Pelanggan sebesar $0,00<0,05$.

\section{Hasil Uji F (Uji Simultan)}

Dari uji Signifikansi Simultan ( Uji Statistik F) dapat diperoleh bahwa nilai $F$ hitung sebesar 63.676 dengan sig. Sebesar 0.000 . Karena probabilitasnya $0.000<0.05$, maka model regresi tersebut dapat dikatakan bahwa visibility, accesibility, dan responsiveness secara bersama-sama berpengaruh terhadap peningkatan kepuasan pasien pada rumah sakit di kota Tegal. Maka hipotesis yang menyatakan ada pengaruh visibility, accesibility, dan responsiveness secara bersama-sama berpengaruh secara simultan terhadap peningkatan kepuasan pasien diterima.

Tabel 4

\section{Hasil Uji F}


ANOVA ${ }^{a}$

\begin{tabular}{|c|l|l|l|l|l|l|}
\hline \multicolumn{2}{|l|}{ Model } & $\begin{array}{l}\text { Sum of } \\
\text { Squares }\end{array}$ & df & $\begin{array}{l}\text { Mean } \\
\text { Square }\end{array}$ & F & Sig. \\
\hline 1 & Regression & 20.236 & 3 & 6.745 & 63.676 & $.000^{\mathrm{b}}$ \\
& \begin{tabular}{l} 
Residual \\
\multicolumn{1}{|c|}{ Total }
\end{tabular} & 14.936 & 141 & .106 & & \\
& 35.172 & 144 & & & \\
\hline
\end{tabular}

a. Dependent Variable: Peningkatan Kepuasan Pelanggan

b. Predictors: (Constant), Responsiveness, Visibility, Accesibility

Sumber : Olahan data SPSS

\section{Kesimpulan}

Kesimpulan dari penelitian ini adalah bahwa variabel visibility, accesibility, dan responsiveness secara bersama-sama berpengaruh terhadap peningkatan kepuasan pasien pada rumah sakit di kota Tegal. Pada pengujian dengan uji t ( uji parsial) diketahui bahwa variabel visibility, accesibility dan responsiveness mempunyai pengaruh positif dan signifikan terhadap peningkatan kepuasan pasien pada rumah sakit di kota Tegal.

\section{Saran}

Berdasarkan hasil penelitian bahwa semua variabel yang diteliti yaitu visibility, accesibility, dan responsiveness berpengaruh positif dan signifikan terhadap peningkatan kepuasan pasien rumah sakit di kota Tegal, maka hendaknya pihak rumah sakit di kota Tegal senantiasa meningkatkan variabelvariabel diatas agar kepuasan pelanggan dapat tercapai secara optimal.

Untuk mengaplikasikan variabel visibility, pihak rumah sakit hendaknya meningkatkan beberapa hal ; kualitas petugas customer service sehingga keluhan pasien dapat tertangani secara langsung, menyedikan layanan telepon/call center/contact center sehingga pasien dapat mengetahui informasi tentang praktek dokter, ketersediaan kamar dll , menyediakan website rumah sakit sehingga pasien dapat mengupdate informasi dan menyediakan kotak saran dan kritik sehingga pasien dapat memberikan saran dan kritik secara tertutup.

Sedangkan untuk mengoptimalkan variabel accesibility, pihak rumah sakit hendaknya melakukan beberapa hal ; memberikan layanan yang mudah kepada pasien,menangani pasien secara cepat dan tidak birokratis sehingga pasien tidak di ping pong. Adapun untuk mengoptimalkan variabel, pihak rumah sakit hendaknya melakukan beberapa hal ; karyawan, paramedis dan dokter membantu pasien dengan tanggap dan cekatan, dan pelayanan administrasi yang tidak bertele-tele.

Untuk penelitian selanjutnya, peneliti menyarankan agar dalam mencari responden lebih banyak lagi dan menambah wilayah geografisnya.

\section{DAFTAR PUSTAKA}

Ghozali, V.2011. Aplikasi Analisis Multivariate dengan Program IBM SPSS 19. Badan Penerbit Universitas Diponegoro. Edisi 5. Semarang.

Hafid, Muh. Anwar.2014, Jurnal Kesehatan :

Volume VII No. 2/2014: Hubungan Kinerja Perawat Terhadap Tingkat Kepuasan Pasien Pengguna Yankestis 
dalam Pelayanan Keperawatan Di RSUD

Syech Yusuf Kab.Gowa

Indrawati, Ayu Desi.( 2013): Jurnal Manajemen, Strategi Bisnis, dan Kewirausahaan Vol. 7, No. 2, Agustus 2013 ; Pengaruh Kepuasan Kerja Terhadap Kinerja Karyawan dan Kepuasan pelanggan pada Rumah sakit Swasta Di Kota Denpasar.

Honny Nur Afidah ( 2013), Keefektifan Pelaksanaan Mekanisme Komplain dalam Pelayanan Kesehatan di Rumah Sakit Umum Haji Surabaya, Kebijakan Manajemen Publik,ISSN 2303 - 341X, Volume 1, Nomor 1, Tahun 2013

Indriantoro dan Supomo.1999. Metodologi Penelitian Bisnis untuk Akuntansi dan Manajemen. Edisi Pertama. BPFE Yogyakarta.Yogyakarta.

Irawan, Andri (2016),http://ejournal.unmus.ac.id/index.ph p/societas, Volume 5 No 01 Tahun 2016.

Kotler, Philip dan Gary Armstrong ,2001, Prinsip-prinsip Pemasaran, Jilid1, Edisi Kedelapan, Jakarta, Erlangga.

Kotler, P.2002, Manajemen Pemasaran : Jakarta : PT Prenhalindo.

Marliana,Lina, 2017,Jurnal Administrative Reform, Vol 5, No 2, Juni 2017

Nurul Afriani ( 2012), Analisis Penangan Keluhan Pelanggan oleh Instalasi Pemasaran dan Humas Rumah Sakit Umum Fatmawati 2012. Skripsi FKM UI,2012.
Tjiptono,Fandy (2008) : Strategi Pemasaran , Yogyakarta : ANDI

Utama,Agung.ISSN $1693-2102$ OPSI, Vol.

1, No. 2, Desember 2003: 96 - 110 :Analisis Pengaruh Persepsi Kualitas Pelayanan Terhadap KepuasanPelanggan Rumah Sakit Umum Cakra Husada Klaten. 